\title{
Human $\mathrm{CD34}^{+}$stem cells produce bone nodules in vivo
}

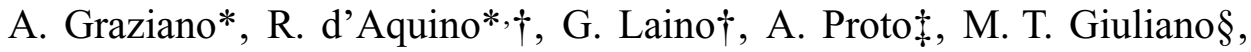 \\ G. Pirozzi $\uparrow$, A. De Rosa†, D. Di Napoli** and G. Papaccio $\dagger$ \\ *Dipartimento di Medicina Sperimentale, Sezione Istologia ed Embriologia, TESLab, Secondo Ateneo di \\ Napoli, Napoli, Italy, †Dipartimento di Discipline Odontostomatologiche, Ortodontiche e Chirurgiche, Secondo \\ Ateneo di Napoli, Napoli, Italy, †Dipartimento di Chimica Università degli Studi di Salerno, Salerno, Italy, \\ $\S$ Dipartimento di Medicina Sperimentale, Sezione di Biotecnologie, Secondo Ateneo di Napoli, Napoli, Italy, \\ $\uparrow$ Oncologia Sperimentale C-Immunologia, Istituto Nazionale Tumori, Napoli, Italy, and **Centro di Biotecnologie, \\ AORN Cardarelli, Napoli, Italy
}

Received 6 March 2007; revision accepted 13 August 2007

\begin{abstract}
Objectives: The aim of this study was to select and provide enough stem cells for quick transplantation in bone engineering procedures, avoiding any in vitro expansion step. Materials and Methods: Dental germ pulp, collected from 25 healthy subjects aged 13-20 years, were subjected to magnetic-activated cell sorting to select a CD34 ${ }^{+}$stem cell population capable of differentiating into pre-osteoblasts. These cells were allowed to adhere to an absorbable polylactic-coglycolic acid scaffold for $30 \mathrm{~min}$, without any prior expansion, and the $\mathrm{CD} 34^{+}$cell-colonized scaffolds were then transplanted into immunocompromised rats, subcutaneously. Results: After 60 days, analysis of recovered transplants revealed that they were formed of nodules of bone, of the same dimensions as the original scaffold. Bone-specific proteins were detected by immunofluorescence, within the nodules, and X-ray diffraction patterns revealed characteristic features of bone. In addition, presence of platelet endothelial cell adhesion molecule and von Willebrand factor immunoreactivity were suggestive of neo-angiogenesis and neovasculogenesis taking place within nodules. Importantly, these vessels were HLA-1 ${ }^{+}$and, thus, clearly human in origin. Conclusions: This study indicates that $\mathrm{CD} 34^{+}$cells obtained from dental pulp can be used for engineering bone, without the need for prior culture expanding procedures. Using autologous stem cells, this schedule could be used to provide the basis for bone regenerative surgery, with limited sacrifice of tissue, low morbidity at the collection site, and significant reduction in time needed for clinical recovery.
\end{abstract}

\section{INTRODUCTION}

Neural crest cells contribute to mesenchymal development of the head and neck. In humans during the sixth week of embryogenesis, ectoderm covering the stomodeum begins to proliferate,

Correspondence: Gianpaolo Papaccio, Department of Experimental Medicine, Section of Histology and Embryology, Second University of Naples, 5 via L. Armanni, 80138 Naples, Italy. Tel.: +39 081-5666015; Fax: +39 081-5666014; E-mail: gianpaolo.papaccio@unina2.it

(Antonio Graziano, Riccardo d'Aquino) These authors equally contributed to the study.

The authors declare that they have no competing financial interests. 
giving rise to the dental laminae. Ecto-mesoderm interactions then lead to placode formation. One of these ovoid ectodermal structures develops into tooth germs, where neural crest cells differentiate into the dental organ, dental papilla and dental follicle. Thus, dental pulp is made up of both ectodermal and mesenchymal components, containing neural crest cells that display plasticity and multipotential capability. After crown mineralization, dental pulp tooth germ remains entrapped within a hard structure that preserves it from environmental differentiation stimuli. Third molar tooth germ begins its maturation around the sixth year of life. Up to this time, embryonic tissues within, remain undifferentiated in the jaw of the postnatal being. Although mineralization of the crown begins during the eighth year, third molar roots are often still incomplete at the age of 18 . This means that structures of these teeth are immature at this age, and development necessitates recruitment of a conspicuous pool of stem cells resident within the dental germ pulp, which acts on the lower face of the germ for root development (Erickson \& Reedy 1998).

A dental pulp stem cell population has been selected from permanent and deciduous teeth by Laino et al. $(2005,2006)$. These cells, selected for c-kit, CD34 and STRO-1 positivity, were found to be able to produce woven bone tissue in vitro. When transplanted autologously in vivo, the tissue then remodelled into lamellar bone. We have also shown that these cells are multipotent, being able to differentiate into adipocytes, neurones and myotubes. Moreover, dental pulp represents an easily accessible source of stem cells that can be cryo-stored for long periods (Papaccio et al. 2006). In humans, the cell-surface antigen CD34 is expressed by primitive stromal and haematopoietic stem cells. It is gradually lost after differentiation into lineage-committed progenitors (Barclay et al. 1988; Simmons \& Torok-Storb 1991; Garcia-Pacheco et al. 2001; Zhang et al. 2003). In the craniofacial region, it has been used to identify multipotent stem cells (Sinanan et al. 2004).

In this study, we show that a CD34 ${ }^{+}$stem cell population can be obtained from dental pulp germs, and that they proliferate and differentiate into pre-osteoblasts, which can then produced bone when transplanted in vivo. These cells can be used for bone tissue production without prior expansion procedures, thus reducing time needed for processing and clinical recovery.

\section{MATERIALS AND METHODS}

\section{Subjects, dental pulp extraction and digestion}

Human dental germ pulp from third molars was extracted from healthy subjects $(n=25)$ aged 13-20 years, following informed consent. Before extraction, each subject was checked for systemic and oral diseases and was pre-treated 1 week previously by a professional dental hygienist. Immediately prior to extraction, the dental crown was covered with $0.3 \%$ chlorexidin gel (Forhans, NY, USA) for 2 min. Dental pulp, extracted with a Gracey curette, was immerzed in a digestion solution [ $3 \mathrm{mg} / \mathrm{mL}$ type I collagenase plus $4 \mathrm{mg} / \mathrm{mL}$ dispase in $4 \mathrm{~mL} 0.1 \mathrm{M}$ phosphatebuffered saline (PBS) supplemented with $100 \mathrm{U} / \mathrm{mL}$ penicillin, $100 \mu \mathrm{g} / \mathrm{mL}$ streptomycin, and $500 \mu \mathrm{g} / \mathrm{mL}$ claritromycin] for $1 \mathrm{~h}$ at $37^{\circ} \mathrm{C}$. Once digested, the solution was filtered with $70 \mu \mathrm{M}$ Falcon strainers (Becton \& Dickinson, Sunnyvale, CA, USA).

\section{Magnetic-activated cell sorting}

After filtration, cells were pelleted and then were incubated with CD34-conjugated beads for $30 \mathrm{~min}$ at $4{ }^{\circ} \mathrm{C}$. After passage through the magnetic-activated cell sorting column (Miltenyi Biotech, Auburn, CA, USA), CD34 ${ }^{+}$cells were immersed in MegaCell culture medium (Sigma, Milan, Italy) supplemented with 10\% FBS, $100 \mu \mathrm{M} 2 \mathrm{P}$-ascorbic acid, $2 \mathrm{~mm}$ L-glutamine, $100 \mathrm{U} / \mathrm{mL}$ 
penicillin, and $100 \mu \mathrm{g} / \mathrm{mL}$ streptomycin (Invitrogen, Milan, Italy). The cell suspension was then centrifuged $(10 \mathrm{~min}$ at $300 \mathrm{~g}$ ), and then the pellet was re-suspended in culture medium. CD34- cells were used as controls.

\section{FACS assay}

Cell samples were analysed after magnetic-activated cell (MAC) selection as follows: cells were washed in $0.1 \%$ bovine serum albumin in $0.1 \mathrm{M}$ PBS at $4{ }^{\circ} \mathrm{C}$, and then were incubated with $10 \mu \mathrm{L}$ antibody. Cells were then washed and assayed with a FACS Vantage (Becton \& Dickinson). Antibodies were the following: anti-c-kit, anti-CD90, anti-CD34 and anti-CD133 (all mouse monoclonal antihuman, Santa Cruz Biotechnology, Santa Cruz, CA, USA). The antibodies were FITC- or PE-conjugated. As control isotype, normal mouse serum was been used.

\section{Colonization of scaffolds}

$\mathrm{CD} 4^{+}$cell pellets were re-suspended in $0.3 \mathrm{~mL}$ culture medium and were layered on absorbable polylactic-coglycolic acid (PLGA) membrane scaffolds (INION, Tampere, Finland), were placed in Petri dishes, and were incubated at $37{ }^{\circ} \mathrm{C}$ with $5 \% \mathrm{CO}_{2}$ for $30 \mathrm{~min}$ to allow colonization. A plating efficiency assay was performed, counting free-floating cells, 30 min later. All experiments were performed in quadruplicate. CD34- cells were placed on identical scaffolds and were used as controls.

\section{In vivo transplantation}

Scaffolds colonized with either $\mathrm{CD}^{+} 4^{+}$or $\mathrm{CD} 34^{-}$cells were transplanted into subcutaneous pockets on the backs of 12 immunocompromised rats, and this condition having been brought about using Cyclosporine $\mathrm{A}$ at a dosage of $15 \mathrm{mg} / \mathrm{kg}$ body weight, administered $24 \mathrm{~h}$ before transplantation and then daily, reducing the dose to $6 \mathrm{mg} / \mathrm{kg}$ over a 2 -week period. This dose was administered until animals were sacrificed, which was 30 or 60 days after transplantation. All procedures were approved by our internal small animal ethics committee.

\section{Alpha-mod17 PCR}

In order to identify the presence of human cells within mouse tissue after recovery of the transplants, $\alpha$-mod17 PCR was been performed. Genomic DNA was isolated by Wizard Genomic DNA purification kit (Promega Corporation, Madison, WI, USA). As controls, 3T3 cells (mouse fibroblasts) and human gingival fibroblasts were used.

\section{Histology and immunofluorescence}

Transplants were recovered, and for routine histology tissues were fixed in $4 \%$ formalin, decalcified with buffered 10\% EDTA pH 7.4 and then were embedded in paraffin wax. Five micromollar sections were cut, de-paraffinized and were stained with haematoxylin and eosin or with Mallory's stain.

For immunofluorescence, tissues were fixed in $100 \%$ ethanol for $30 \mathrm{~min}$ at $4{ }^{\circ} \mathrm{C}$, were washed in $0.1 \mathrm{M}$ PBS, then were left for $60 \mathrm{~min}$ in $\mathrm{PBS} / 6 \%$ milk and were incubated overnight with antibodies at $4{ }^{\circ} \mathrm{C}$. Antibodies, diluted $1 / 100$, were the following: osteonectin, fibronectin (Novo Castra, Newcastle, UK), BSP (bone sialoprotein, BIODESIGN International, Kennebunk, ME, USA), BAP (bone alkaline phosphatase, US Biological, Swampscott, MA, USA), all mouse antihuman; osteocalcin (OC), platelet endothelial cell adhesion molecule and von Willebrand factor antibodies (Santa Cruz Biotechnology) were antihuman raised in goat. Secondary antibodies were goat antimouse (FITC) and mouse antigoat (PE) (Santa Cruz Biotechnology); dilution of these was $1 / 200$. Samples were then observed using fluorescence microscopy (Axiovert 100, 
Zeiss, Germany). Specificity of immunostaining was assessed using control isotypes (normal mouse serum) for primary antibodies. In order to assess the human origin of the tissue, immunofluorescence with an anti-HLA-1 antibody was performed. To evaluate the percentage of HLA$1^{+}$cells, we FACS analysed samples from three transplanted tissues, collected at each time of sacrifice. Cell suspensions were obtained after digestion of bone nodules with the same solution used for isolation of the cells from the dental pulp.

\section{X-ray diffraction analysis}

For X-ray powder diffraction analysis, transplant samples also were obtained at sacrifice. As control, intraoral mandibular cortex samples from the same patients were analysed. The X-ray diffraction pattern was recorded on a Philips PW1710 powder diffractometer (Philips, Eindhoven, The Netherlands) operating at $45 \mathrm{kV}, 30 \mathrm{~mA}$ and 2 degrees $2 \Theta /$ min scan rate with $\mathrm{Cu} \mathrm{K \alpha}$ radiation.

\section{RESULTS}

Individual dental pulps provided sufficient tissue for digestion and selection of $\mathrm{CD}_{3} 4^{+}$cells, avoiding any in vitro expansion steps. MAC sorting produced an average of $20000 \pm$ $5000 \mathrm{CD}^{+} 4^{+}$cells for each dental germ pulp (Fig. 1a,b), starting from $1000000 \pm 100000$. After 30 min seeding on the PGLA scaffolds, roughly $92 \%$ of CD $34^{+}$cells adhered to the membranes. FACS analysis of MAC-sorted cell samples showed that $90 \%$ of $\mathrm{CD} 34^{+}$cells were also CD $117^{+}$ (Fig. 1c). This indicated that this cytotype was the same as previously selected and recorded by our group (Laino et al. 2005, 2006). Almost $100 \%$ of CD $34^{+}$cells were also CD $90^{+}$and CD133 ${ }^{+}$ (Fig. 1d).

After 60 days of transplantation, immunofluorescence analysis of sections obtained from grafts revealed that bone formation had occurred on the PLGA membranes. This bone tissue was HLA- $1^{+}$, thus of human origin (Fig. 2a); BSP was detectable in peripheral areas of bone nodules where a periosteal layer was found. OC positivity was intense and diffuse, like BAP and ON (Fig. 2b-e). Detection of human neo-angiogenesis and neovasculogenesis was assessed by platelet endothelial cell adhesion molecule (Fig. 3a,b) and von Willebrand expression (Fig. 3c,d). Human origin of the vessels was established by HLA-1 (Fig. 3e,f). Presence of human cells was assessed by RT-PCR (Fig. 3g); the percentage of HLA- $1^{+}$cells within each nodule was $89.9 \pm 0.8$ (Fig. $3 \mathrm{~h}$ ); control isotypes were negative. Membranes coated with CD34- cells showed no presence of bone nodules (Fig. 4).

Bone formation was seen to occur in two main steps. At day 30, fibrous bone was observed; this then remodelled into adult-type bone tissue by day 60 (Fig. 5a,b). PLGA membrane reabsorption was almost complete at day 60; at this time, only $0.1 \mathrm{~mm}$ lengths of membrane were observable within bone nodules (Fig. 5c,d). Interestingly, the dimensions of the bone nodules were similar to the original dimensions of the scaffolds, indicating that growth was regulated by the adhesion surface.

X-ray diffraction analyses indicated that bone obtained after transplantation was composed of typical crystals of human bone, the sole exception being presence of fluorapatite. This is commonly present in adult lamellar bone only after remodelling processes requiring osteoclast activity. The X-ray diffraction pattern obtained from recovered transplanted samples was superimposable on those belonging to the control sample removed from the mandible of each patient. Shifts seen on the $Y$ axis among the two is due to lesser maturation of the transplanted sample (Fig. 6). Day 60 samples presented increased mineralization with respect to samples at day 30. 
(a)

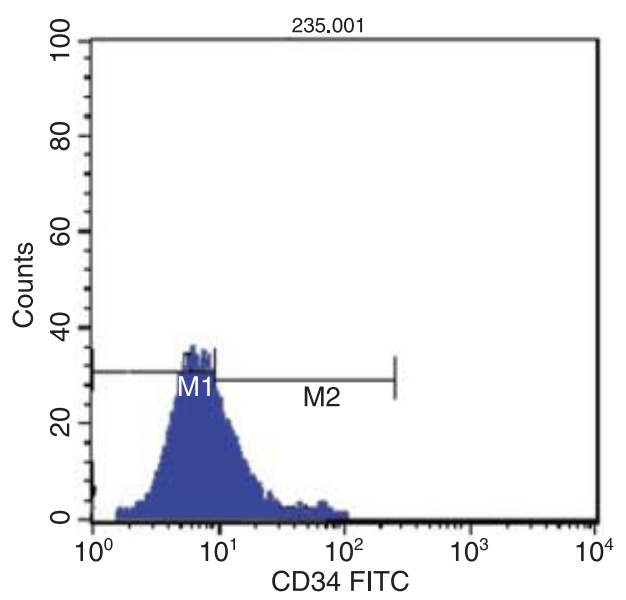

(c)

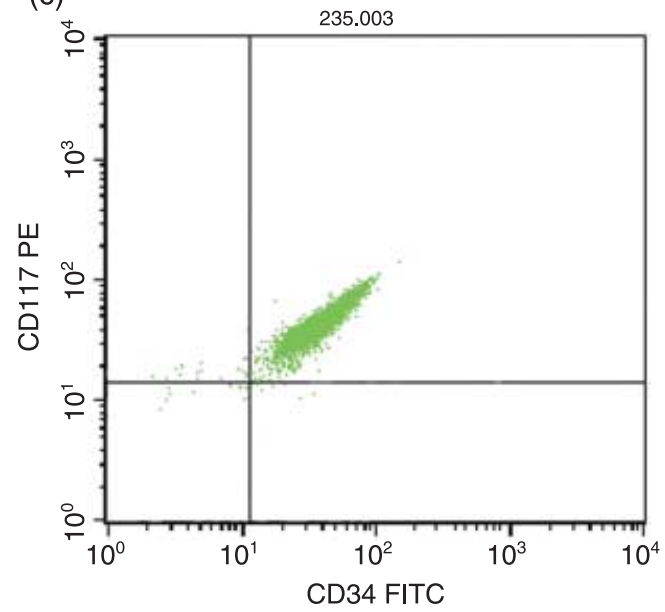

(b)

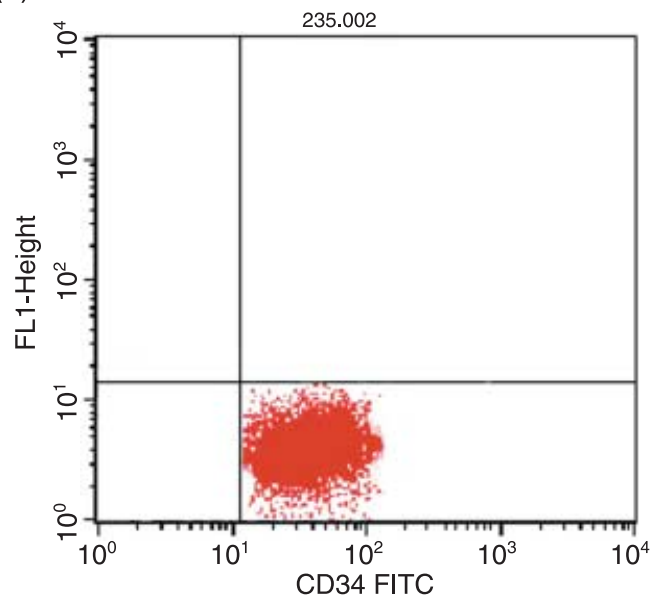

(d)

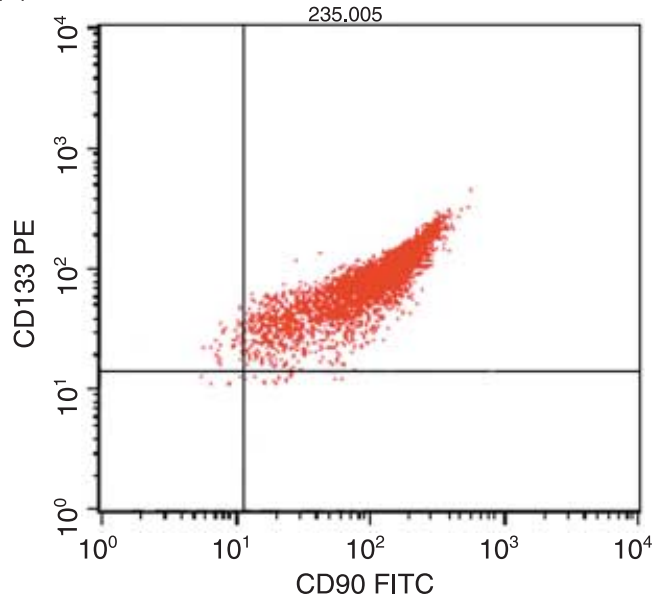

Figure 1. Flow cytometric analysis of cells, performed after digestion before (a) and after (b) CD34 MACS selection. CD34 ${ }^{+}$cells were also positive for CD117 (c), CD90 and CD133 (d).

\section{DISCUSSION}

Here, we describe the remarkable ability of human $\mathrm{CD} 34^{+}$germ pulp stem cells, explanted from adult human teeth, to differentiate into osteoblasts. When transplanted in vivo on a PLGA membrane, these cells produced bone nodules of the same dimensions as the original scaffold.

Dental pulp is a good source of stem cells (Gronthos et al. 2000; Gronthos et al. 2002; Miura et al. 2003) that differentiate into osteoblasts, as well as other phenotypes, for hard tissue engineering (Laino et al. 2006). During life, bone tissue needs renewal, and dental pulp represents an additional source of mesenchymal cells to bone marrow (Laino et al. 2005). Selection and expansion of stem cells are complex procedures commonly used to obtain cells for potential therapy (Both et al. 2007; Hofmeister et al. 2007); thus, being able to obtain sorted cells quickly after collection then being able to transplant them directly is an advantage that can lead to easier application of bone-engineering protocols (Aslan et al. 2006). 

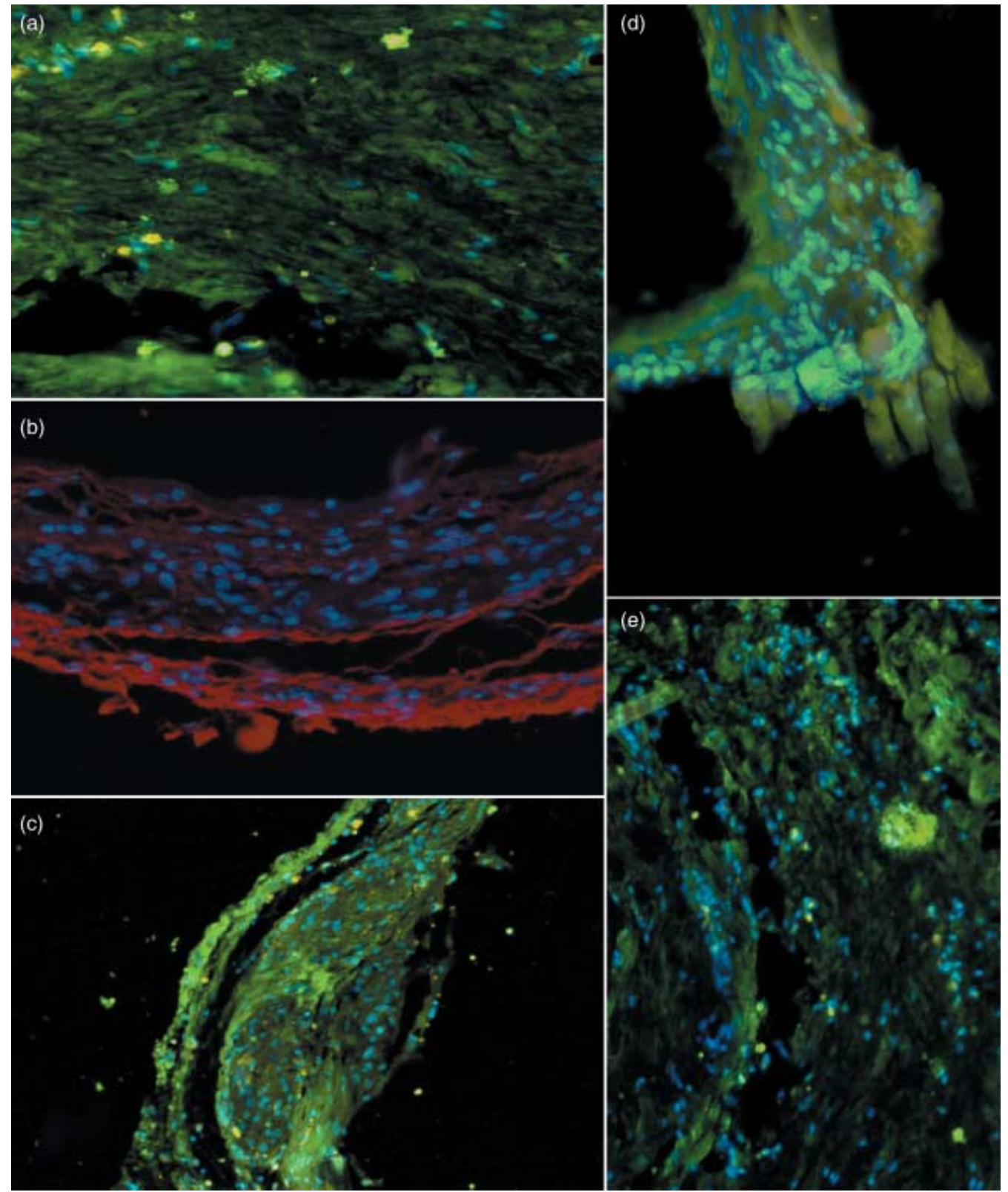

Figure 2. Immunofluorescence confirming the presence of HLA-1 (a) (original magnification $\times 200$ ) and of a mineralized extracellular matrix of the transplant. The panel shows positivity for BSP (b) (original magnification $\times 200$ ), OC (c) (original magnification $\times 100$ ), BAP $(d)$ (original magnification $\times 200$ ) and $\mathrm{ON}(\mathrm{e})($ original magnification $\times 200)$.

In humans, CD34 is a single-chain transmembrane glycoprotein expressed on human haematopoietic stem and mesenchymal progenitor cells (Javazon et al. 2004). Although it is currently used in clinical applications of stem cell therapy with cells of haematopoietic origin, its presence is not detectable in mesenchymal stem cells from bone marrow (Liu et al. 2006; Lee 

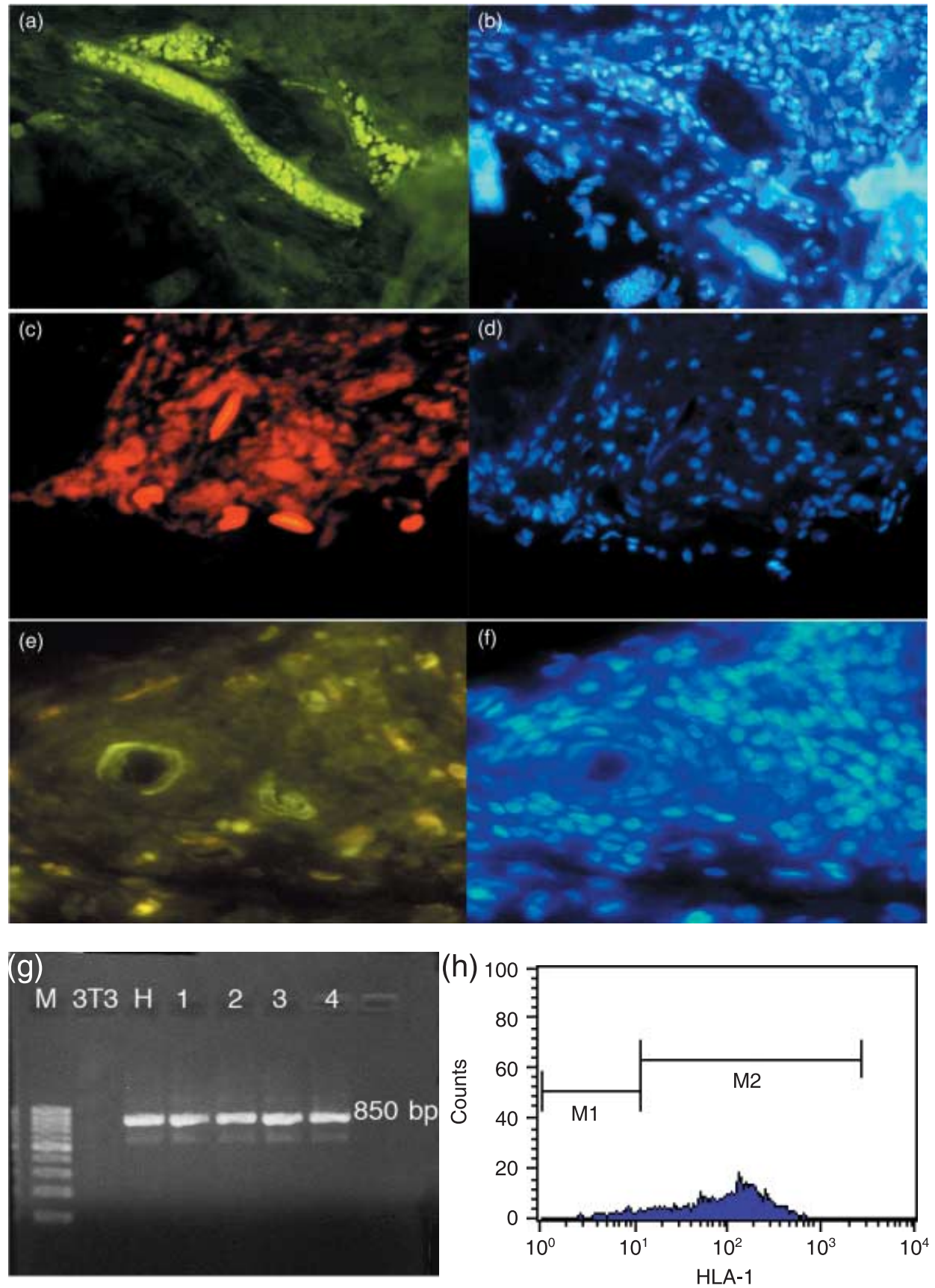

Figure 3. Immunofluorescence showing platelet/endothelial cell adhesion molecule-1 (PECAM-1), von Willebrand factors 1/2 and HLA-1 positive vessels within bone obtained after 60 days of transplantation. (a) PECAM-1 positivity and (b) DAPI counterstaining (Original magnification $\times 200$ ); (c) von Willebrand factor $1 / 2$ positivity and (d) DAPI counterstaining (Original magnification $\times 100$ ); (e) HLA-1 positivity and (f) DAPI counterstaining (Original magnification $\times 400)$; $(\mathrm{g})$ to identify the presence of human cells within mouse tissues, $\alpha$-mod17 PCR has been performed. Lane 1: 3 T3 cells (mouse fibroblasts); lane 2: human gingival fibroblasts; lane 3-6: 1-4 test samples. (h) FACS analysis showing HLA-1 positivity in cells obtained from transplants at both sacrifice times. 


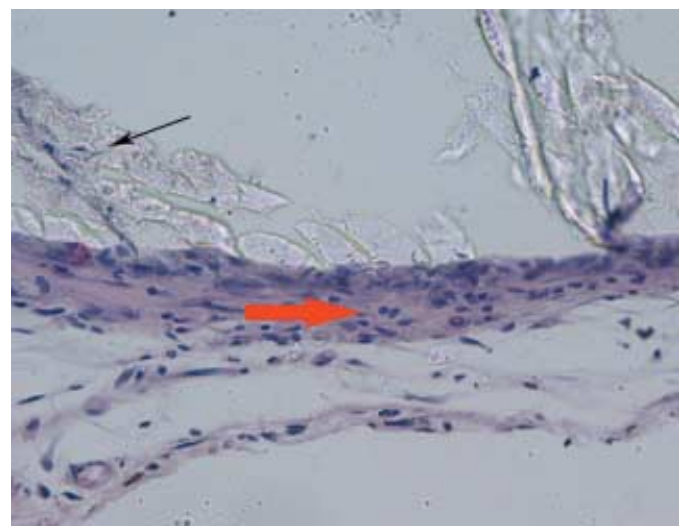

Figure 4. Haematoxylin and eosin staining. In vivo sample produced with CD34- cells. No bone nodules were formed, only connective tissue (red arrow) and PLGA (black arrow) can be observed (original magnification $\times 200$ ).
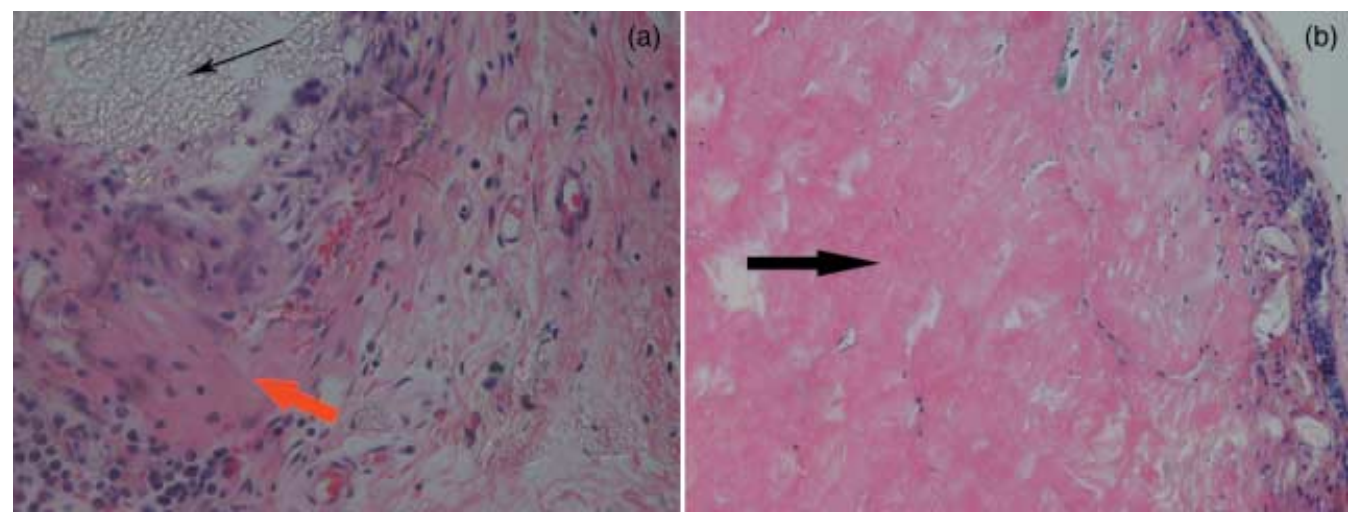

Figure 5. Haematoxylin and eosin staining. In vivo sample produced with CD $34^{+}$cells. (a) Sample after 30 days, in which small fragments of non-absorbed PLGA (black arrow) and a fibrous bone tissue (red arrow) are present (original magnification $\times 400$ ). (b) Sample after 60 days showing remodelled, newly formed bone (arrow) (original magnification $\times 200)$.

et al. 2007); its expression in bone marrow stem cell-derived bone progenitors has not been definitively demonstrated (Jiang et al. 2002; Sinanan et al. 2004). Although CD34 has never been extensively used in experimental models of bone-tissue engineering, it must be considered that in mesenchymal stem cell, CD34 expression might be detectable from sources such as adipose tissue (Yoshimura et al. 2006), and by other cell types, such as the mesangioblast, that can give rise to bone progenitors too (Pelosi et al. 2002; Yoshimura et al. 2006).

In our previous studies, we have demonstrated that CD34, in association with CD117, can be used to select a population of dental pulp stem cells able to differentiate into pre-osteoblasts in vitro (Laino et al. 2005, 2006). These cells produce a well-differentiated bone matrix, with a fully developed vascular supply, when transplanted in vivo. Both osteogenic and angiogenic cytoypes can be found in the human dental pulp stem cell $\left(\mathrm{CD} 34^{+} / \mathrm{c}-\mathrm{kit}^{+} / \mathrm{STRO}-1^{+}\right)$population (d'Aquino et al. 2007). 


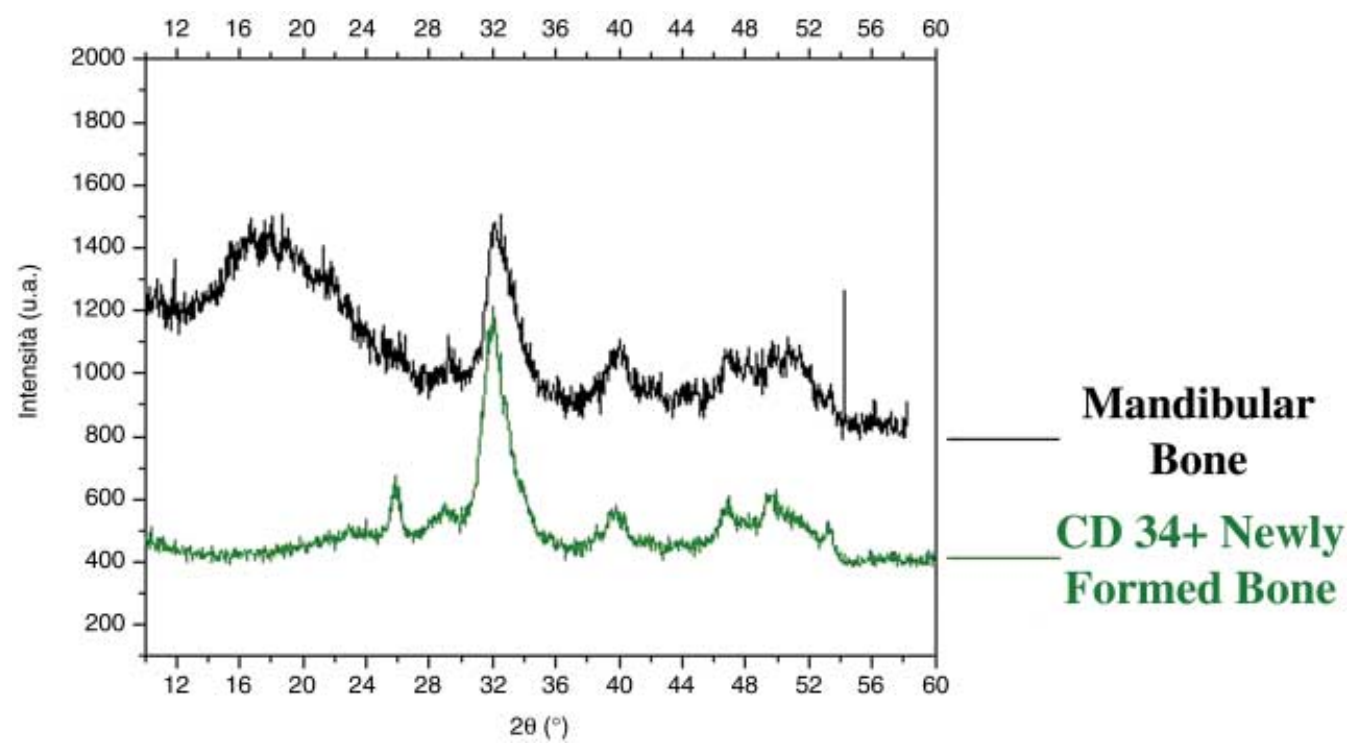

Figure 6. X-ray diffraction analysis of a sample of mandibular cortex (in black) and of a 60-day-old transplant (in green). Typical crystals of human bone can be seen. The diffraction X-ray diffraction pattern is completely superimposable onto that of the control sample (in black). Different positions on the $Y$ axis of the two samples are due to immaturity of the tissue. Analyses were repeated in quadruplicate without appreciable differences between samples.

In this study, we demonstrate the feasibility of selecting cells from germ pulp with magnetic beads and using them for bone production, without any prior in vitro expansion steps. Thus, selection of cells was faster and easier, and time needed for cell processing was greatly reduced. Adhesion of MAC-selected cells on PLGA scaffolds was achieved within 30 min from seeding, and these cells were osteogenic when transplanted in vivo. After 60 days, almost all of the PLGA membrane was re-absorbed, leaving bone nodules at the site of surgery. This indicated that the PLGA membrane (Saitoh et al. 1994; Hutmacher et al. 2003) was a suitable scaffold for transplantation of MAC-selected cells. The scaffold is a very important structure for bone generation, and the re-absorbance rate should be tuned according to the timing of cell differentiation. PLGA performs well with regard to supporting cells and is re-absorbed after bone differentiation; it can be carved and designed according to the surgeon's needs. Well-differentiated bone extracellular matrix was found in transplants already at 30 days after implantation, and by day 60, the mineralization rate of transplants was superimposable to that observed in human mandibular bone samples.

Physiologically, dental pulp progenitor cells give rise to dentine, but factors implied in this morphogenetic phenomenon are all of ectodermal origin (Yuasa et al. 2004). In order to give rise dentine, ameloblasts (of ectodermal origin) secrete factors (Lesot et al. 2001) that stimulate dental pulp progenitor cells to become odontoblasts, that are terminally differentiated variants of osteoblasts, which give rise to dentine formation (Yuasa et al. 2004). When these ectodermal factors are lacking, the same progenitor cells (Bosshardt 2005) are capable of becoming osteoblasts and of forming fibrous bone that, histologically, is similar to tertiary dentine (Boskey 1991). The latter is physiologically generated by dental pulp stem cells after injury, against hard tissues of the tooth (Sloan \& Smith 2007). Dental pulp stem cells produce BMP2 and VEGF 
(Graziano et al. 2007), and factors involved in osteogenic commitment of human stem cells (Huang et al. 2005; Peng et al. 2005). Importantly here, the absence of bone marrow in the bone nodules should be considered in the perspective that dental pulp is different from medullar bone due to its contrasting embryonic origin and function (Helms \& Schneider 2003).

As demonstrated in this account, human dental pulp is a source capable of providing enough stem cells for quick transplantation in bone-engineering procedures, avoiding any in vitro expansion step. This protocol can be transferred to clinical practice to provide autologous mesenchymal stem cells for bone surgery with limited sacrifice of human tissues and morbidity of the collection site.

\section{ACKNOWLEDGEMENTS}

This study was supported by MIUR (Project of relevant interest 2005 to GP), 2nd University of Naples (2004/06 grants to GP) and Campania Region grant (2005 to GP).

The authors thank the Center of Biotechnologies of AORN A. Cardarelli, Naples, Italy, for the technical supplies.

\section{REFERENCES}

Aslan H, Zilberman Y, Kandel L, Liebergall M, Oskouian RJ, Gazit D, Gazit Z (2006) Osteogenic differentiation of noncultured immunoisolated bone marrow-derived CD105+ cells. Stem Cells 24, 1728-1737.

Barclay AN, Jackson DI, Willis AC, Williams AF (1988) The leukocyte-common antigen (L-CA) family. Adv. Exp. Med. Biol. 237, 3-7.

Boskey AL (1991) The role of extracellular matrix components in dentin mineralization. Crit. Rev. Oral Biol. Med. 2, 369-387.

Bosshardt DD (2005) Are cementoblasts a subpopulation of osteoblasts or a unique phenotype? J. Dent. Res. 84, $390-406$.

Both SK, Muijsenberg AJ, Blitterswijk CA, Boer JD, Bruijn JD (2007) A rapid and efficient method for expansion of human mesenchymal stem cells. Tissue Eng. 13, 3-9.

d'Aquino R, Graziano A, Sampaolesi M, Laino G, Pirozzi G, De Rosa A, Papaccio G (2007) Human postnatal dental pulp cells co-differentiate into osteoblasts and endotheliocytes: a pivotal synergy leading to adult bone tissue formation. Cell Death Differ. 14, 1162-1171.

Erickson CA, Reedy MV (1998) Neural crest development: the interplay between morphogenesis and cell differentiation. Cur. Top. Dev. Biol. 40, 177-209.

Garcia-Pacheco JM, Oliver C, Kimatrai M, Blanco FJ, Olivares EG (2001) Human decidual stromal cells express CD34 and STRO-1 and a related bone-marrow stromal precursors. Mol. Hum. Reprod 7, 151-157.

Graziano A, d'Aquino R, Cusella-De Angelis MG, Laino G, Piattelli A, Pacifici M, De Rosa A, Papaccio G (2007) Concave pit-containing scaffold surfaces improve stem cell-derived osteoblast performance and lead to significant bone tissue formation. PLOS ONE 2, e496.

Gronthos S, Brahim J, Li W, Fisher LW, Cherman N, Boyde A, Denbesten P, Robey PG, Shi S (2002) Stem cell properties of human dental pulp stem cells. J. Dent. Res. 81, 531-535.

Gronthos S, Mankani M, Brahim J, Robey PG, Shi S (2000) Postnatal human dental pulp stem cells (dpscs) in vitro and in vivo. Proc. Natl. Acad. Sci. USA 97, 13625-13630.

Helms JA, Schneider RA (2003) Cranial skeletal biology. Nature 423, 326-331.

Hofmeister CC, Zhang J, Knight KL, Le P, Stiff PJ (2007) Ex vivo expansion of umbilical cord blood stem cells for transplantation: growing knowledge from the hematopoietic niche. Bone Marrow Transplant 39, 11-23.

Huang YC, Kaigler D, Rice KG, Krebsbach PH, Mooney DJ (2005) Combined angiogenic and osteogenic factor delivery enhances bone marrow stromal cell-driven bone regeneration. J. Bone Miner. Res. 20, 848-857.

Hutmacher DW, Ng KW, Kaps C, Sittinger M, Klaring S (2003) Elastic cartilage engineering using novel scaffold architectures in combination with a biomimetic cell carrier. Biomaterials 24, 4445-4458. 
Javazon EH, Beggs KJ, Flake AW (2004) Mesenchymal stem cells: paradoxes of passaging. Exp. Hematol. 32, $414-425$.

Jiang Y, Jahagirdar BN, Reinhardt RL, Schwartz RE, Keene CD, Ortiz-Gonzalez XR, Reyes M, Lenvik T, Lund T, Du Blackstad MJ, Aldrich S, Lisberg A, Low WC, Largaespada DA, Verfaillie CM (2002) Pluripotency of mesenchymal stem cells derived from adult marrow. Nature 418, 41-49.

Laino G, d'Aquino R, Graziano A, Lanza V, Carinci F, Pirozzi G, Naro F, Papaccio G (2005) Dental pulp stem cells can be detected in aged humans: an useful source for living autologous fibrous bone tissue (LAB). J. Bone Miner. Res. 20, 1394-1402.

Laino G, Graziano A, d'Aquino R, Pirozzi G, Lanza V, Valiante S, De Rosa A, Naro F, Vivarelli E, Papaccio G (2006) An approachable human adult stem cell source for hard-tissue engineering. J. Cell. Physiol. 206, 693-701.

Lee SY, Miwa M, Sakai Y, Kuroda R, Matsumoto T, Iwakura T, Fujioka H, Doita M, Kurosaka M (2007) In vitro multipotentiality and characterization of human unfractured traumatic hemarthrosis-derived progenitor cells: a potential cell source for tissue repair. J. Cell. Physiol. 210, 561-566.

Lesot H, Lisi S, Peterkova R, Peterka M, Mitolo V, Ruch JV (2001) Epigenetic signals during odontoblast differentiation. Adv. Dent. Res. 15, 8-13.

Liu L, Sun Z, Chen B, Han Q, Liao L, Jia M, Cao Y, Ma J, Sun Q, Guo M, Liu Z, Ai H, Zhao RC (2006) Ex vivo expansion and in vivo infusion of bone marrow-derived Flk- $1^{+} \mathrm{CD} 31^{-} \mathrm{CD} 34^{-}$mesenchymal stem cells: feasibility and safety from monkey to human. Stem Cells Dev. 15, 349-357.

Miura M, Gronthos S, Zhao M, Lu B, Fisher LW, Robey PG, Shi S (2003) SHED: stem cells from human exfoliated deciduous teeth. Proc. Natl. Acad. Sci. USA 100, 5807-5812.

Papaccio G, Graziano A, d'Aquino R, Graziano MF, Pirozzi G, Menditti D, De Rosa A, Carinci F, Laino G (2006) Longterm cryopreservation of dental pulp stem cells (SBP-dpscs) and their differentiated osteoblasts: a cell source for tissue repair. J. Cell. Physiol. 208, 319-325.

Pelosi E, Valtieri M, Coppola S, Botta R, Gabbianelli M, Lulli V, Marziali G, Masella B, Muller R, Sgadari C, Testa U, Bonanno G, Peschle C (2002) Identification of the hemangioblast in postnatal life. Blood 100, 3203-3208.

Peng H, Usas A, Olshanski A, Ho AM, Gearhart B et al. (2005) VEGF improves, whereas sflt1 inhibits, BMP2-induced bone formation and bone healing through modulation of angiogenesis. J. Bone Miner. Res. 20, 2017-2027.

Saitoh H, Takata T, Nikai H, Shintani H, Hyon SH, Ikada Y (1994) Effect of polylactic acid on osteoinduction of demineralized bone: preliminary study of the usefulness of polylactic acid as a carrier of bone morphogenetic protein. J. Oral Rehabil. 21, 431-438.

Simmons PJ, Torok-Storb B (1991) CD34 expression by stromal precursors in normal human adult bone marrow. Blood 78, 2848-2853.

Sinanan AC, Hunt NP, Lewis MP (2004) Human adult craniofacial muscle-derived cells: neural-cell adhesion-molecule (NCAM; CD56)-expressing cells appear to contain multipotential stem cells. Biotechnol. Appl. Biochem. 40, $25-34$.

Sloan AJ, Smith AJ (2007) Stem cells and the dental pulp: potential roles in dentine regeneration and repair. Oral Dis. 13, 151-157.

Yoshimura K, Shigeura T, Matsumoto D, Sato T, Takaki Y, Aiba-Kojima E, Sato K, Inoue K, Nagase T, Koshima I, Gonda K (2006) Characterization of freshly isolated and cultured cells derived from the fattyand fluid portions of liposuction spirates. J. Cell. Physiol. 208, 64-76.

Yuasa K, Fukumoto S, Kamasaki Y, Yamada A, Fukumoto E, Kanaoka K, Saito K, Harada H, Arikawa-Hirasawa E, Miyagoe-Suzuki Y, Takeda S, Okamoto K, Kato Y, Fujiwara T (2004) Laminin alpha2 is essential for odontoblast differentiation regulating dentinsialoprotein expression. J. Biol. Chem. 279, 10286-10292.

Zhang J, Niu cyel, Huang H, He X, Tong WG, Ross J, Haug J, Johnson T, Feng JQ, Harris S, Wiedemann LM, Mishina Y, Li L (2003) Identification of the haematopoietic stem cell niche and control of the niche size. Nature 425, $836-840$ 